\title{
CATA-VENTOS PEDAGógICOS: UMA PROPOSTA METODOLÓGICA PARA CURSOS DE GRADUAÇÃO NA MODALIDADE EaD EM UMA IES COMUNITÁRIA
}

WIND-VANES:
A METHODOLOGICAL ORGANIZATION PROPOSAL FOR
UNDERGRADUATE COURSES IN EaD MODALITY
MOLINILLOS PEDAGÓGICOS:
UNA PROPUESTA DE ORGANIZACIÓN CURRICULAR METODOLÓGICA PARA LOS
CURSOS DE GRADUACIÓN EN LA MODALIDAD DE EDUCACIÓN A DISTANCIA
Ereice Scremin ${ }^{1}$
Eliane Aparecida Galvão dos Santos
Elisiane Machado Lunardi
RESUMo: A necessidade de repensar a formação de profissionais para a atuação na sociedade contemporânea
vem desafiando os cursos de formação em termos curriculares e metodológicos. Este artigo tem por objetivo
apresentar e discutir a proposta metodológica de uma IES comunitária e confessional para Cursos de Graduação,
na modalidade EaD.. Trata-se de um estudo qualitativo, do bibliográfico e documental. A proposta, está pautada
nos princípios de relação dialógica, flexibilidade curricular, relação teoria-prática e tecnologia aplicada à
educação, a partir de atividades de ensino, pesquisa e extensão. Nesse processo, a proposta denominada Cata-
ventos Pedagógicos esta articulada em núcleos, módulos temáticos e unidades de aprendizagem. Depreende-se
que a proposiçãa de novas modalidades de ensino e de inovações metodológicas precisam buscar inovações em
relação ao paradigma curricular vigente de formação. Para tanto, faz-se necessário o engajamento da gestão
institucional, investindo na valorização da mudança, em infraestrutura e na formação dos professores. Por parte
dos docentes, é fundamental que eles assumam o compromisso com o novo projeto e com a reorganização dos
tempos e espaços de aprendizagem.

PALAVRAS-CHAVE: Inovação. Currículo. Ensino superior. Educação a distância.

ABSTRACT: The need to rethink the training of professionals to work in contemporary society has challenged the training courses in curricular and methodological terms. This article has the objective of presenting and discussing a curricular proposal that constitutes a reference for the elaboration of the Pedagogical Projects of the Undergraduate Courses, in distance learning (DL) modality, of a communitary and confessional higher education institution (HEI). This is a qualitative exploratory and documentary study. The proposal, denominated Pedagogical Wind-vanes, is based on the principles of dialogic relationship, curricular flexibility, theory-practice relationship and technology applied to education, based on teaching, research and extension activities. It is a curricular organization that articulates nuclei, thematic modules and learning units. The proposition of new modalities of teaching must seek something new in relation to the current curricular paradigm of formation. To do so, it is necessary to engage in institutional management, investing in the valuation of change, in infrastructure and in the training of teachers. On the part of the teachers, it is fundamental that they assume the commitment with the new project and with the reorganization of the times and spaces of learning.

KEYWORDS: Innovation. Curriculum. Higher education. Distance learning.

Submetido em: 03/03/2018 - Aceito em: 16/04/2018 - Publicado em: 28/05/2018

\begin{tabular}{l|l|l|l|l|l|} 
(C) Rev. Inter. Educ. Sup. & Campinas, SP & v.4 & n.3 & p.510-520 & set./dez. 2018 \\
\hline
\end{tabular}


RESUMEN: La necesidad de repensar la formación de profesionales para la actuación en la sociedad contemporánea desafía los cursos de formación en términos curriculares y metodológicos. Este artículo tiene el objetivo de presentar y discutir una propuesta curricular que se constituye como referencia para la elaboración de Proyectos Pedagógicos de los Cursos de Graduación, en la modalidad de educación a distancia de una Institución de Enseñanza Superior comunitaria y confesional. Este es un estudio cualitativo, del tipo exploratorio y documental. La propuesta, denominada molinillos pedagógicos, está basada en los principios de relación dialógica, flexibilidad curricular, relación teoría-práctica y tecnología aplicada a la educación, a partir de actividades de enseñanza, investigación y extensión. Se trata de una organización curricular que articula núcleos, módulos temáticos y unidades de aprendizaje. La proposición de nuevas modalidades de enseñanza y de innovaciones curriculares es fundamental para lograr los objetivos formativos contemporáneos. Tales propuestas buscan algo nuevo con relación al paradigma curricular vigente de formación. Para eso, se hace necesario el compromiso de la gestión institucional, invistiendo en la valorización del cambio, en infraestructura y en la formación de los profesores. También es fundamental que los docentes asuman el compromiso con el nuevo proyecto y con la reorganización de los tiempos y espacios de aprendizaje.

PALABRAS ClAVE: Innovación. Currículo. Enseñanza superior. Educación a distancia.

\section{INTRODUÇÃO}

A sociedade atual vive em constante transformação e, diante das inovações tecnológicas, a demanda por profissionais cada vez mais dinâmicos e polivalentes é um desafio para as instituições formadoras. Nesse contexto, torna-se questionável o emprego de metodologias passivas, que não desenvolvam a autonomia dos estudantes, por parte das universidades.

Dessa forma, uma preocupação que precisa permear os cursos de formação de futuros profissionais é a de repensar o processo formativo, a fim de contribuir com a renovação do ensino nas universidades, buscando a superação de paradigmas tradicionais que levam à fragmentação e simples reprodução do conhecimento.

A necessidade de se pensar em um currículo inovador, que buscasse desconstruir a ideia de disciplinas isoladas, bem como a adequação às características do estudante contemporâneo que procura a Educação a Distância - EaD foram os motivos que contribuíram para o investimento na implementação da $\mathrm{EaD}$ em uma instituição de ensino superior do interior do Rio Grande do Sul, Brasil.

Assim, este trabalho apresenta e discute a proposta metodológica de uma IES comunitária e confessional para Cursos de Graduação, na modalidade EaD. Aponta-se que a EaD, no contexto brasileiro, a EaD teve destaque na década de 70, a partir de um acordo entre a Universidade de Brasília Unb) e a Open University do Reino Unido quando a UnB passou a oferecer cursos de extensão na modalidade que permitia uma abrangência de todos os estados brasileiros (FONTANA, et al, 2014). Nesse contexto, é possível referir que, desde a Lei de Diretrizes e Bases da Educação 4.024/61 (que indica a possibilidade de educação por essa modalidade), até o Decreto de Lei 5.622/05 (que caracteriza a EaD pelo poder público como modalidade educacional) foram fundamentais para impulsionar o progresso da $\mathrm{EaD}$ como

\begin{tabular}{l|l|l|l|l|l} 
(C) Rev. Inter. Educ. Sup. & Campinas, SP & v.4 & n.3 & p.510-520 & set./dez. 2018 \\
\hline
\end{tabular}


efetiva possibilidade no campo educacional de flexibilização de horários, sem perder de vista a qualidade do ensino.

As ações no âmbito da Educação a Distância, na instituição de que trata este trabalho, tiveram início no final dos anos 90, quando a IES passou a utilizar o ambiente virtual de aprendizagem - Moodle como apoio às aulas presenciais. Desde o ano de 2000, promove-se o processo formativo permanente para os profissionais da instituição com o enfoque nas tecnologias digitais. Em 2011, foi projetado um espaço virtual que tem por objetivo elaborar e publicar conteúdos didáticos digitais como objetos de aprendizagem, produzidos por professores dos cursos de graduação. Em 2013, iniciou-se a construção das propostas metodológicas para os cursos de graduação na modalidade EAD. Nessa fase, foi constituído uma equipe de trabalho em que foram designados, pela Reitoria da instituição, professores das mais diversas áreas do conhecimento, entre elas Pedagogia, Jornalismo, Ciências Econômicas e Ciência da Computação. Os primeiros cursos a serem elaborados foram Pedagogia e o Curso Superior de Tecnologia em Gestão de Recursos Humanos (CSTGRH). Assim, a partir do Projeto Pedagógico Institucional e no Plano de Desenvolvimento Institucional construiu-se a proposta metodológica aqui apresentada para o curso de Pedagogia.

Nesse processo, buscou-se construir um pensamento reflexivo sobre $\mathrm{EaD}$, a partir de articulações interdisciplinares agregando as áreas de pedagogia, de tecnologia da informação e de comunicação. Foi nesse contexto que a equipe de trabalho constituída por professores do curso de Pedagogia mobilizou-se para a construção de uma proposta que rompesse com o pensamento compartimentado do conhecimento e fosse mediada pela utilização das novas tecnologias educacionais.Tratou-se de um estudo qualitativo, do tipo, bibliográfico e documental que culminou em uma proposta metodológica a qual constitui-se como base para a criação de novos cursos de graduação na modalidade EaD da instituição.

As propostas curriculares para o ensino superior têm como pressuposto uma concepção abrangente de currículo como "conjunto de conhecimentos, saberes, competências, habilidades, experiências, vivências e valores organizados de forma integrada" (MASSETTO, 2011, p. 4). Essa visão congrega com a proposta discutida nesse trabalho, pois preconiza que tais vivências sejam desenvolvidas de forma integrada por meio de metodologias que, promovam a prática da interdisciplinaridade, relações entre a teoria e a prática, entre a ciência e a tecnologia, segundo o paradigma filosófico da instituição (CENTRO UNIVERSITÁRIO FRANCISCANO, 2016).

Considera-se assim que as propostas curriculares precisam projetar perspectivas e novas possibilidades, ultrapassando limites e pensando um ensino superior que responda às exigências atuais e futuras. Assim, este texto está organizado em dois tópicos que exploram as concepções e princípios norteadores da proposta, bem como a organização curricular para

\begin{tabular}{|l|l|l|l|l|l|}
\hline (c) Rev. Inter. Educ. Sup. & Campinas, SP & v.4 & n.3 & p.510-520 & set./dez. 2018 \\
\hline
\end{tabular}


cursos em EaD, destacando a relevância dessa modalidade como base para a elaboração de outros cursos de EaD na instituição.

\section{PROPOSTA de ORGANIZAÇÃo METOdológiCA PARA CURSOS NA MODALIDADE EaD}

O conhecimento é um processo que se constrói de forma individual e coletivamente, sendo resultado da interpretação e da compreensão das informações que são internalizadas pelos sujeitos a partir do significado que ele atribui à realidade e de como ela é contextualizada.

Nessa perspectiva, o currículo pode ser compreendido como

[...] um conjunto de aprendizagens que, por se considerarem social e profissionalmente necessárias num dado tempo e contexto, cabe à Instituição escolar garantir e organizar e é assumido como um projeto no qual participam ativamente professores e alunos em sua elaboração, execução e avaliação (MASETTO, 2011, p. 16).

Esse conjunto de aprendizagens é, portanto, de responsabilidade da instituição formadora que precisa constituir um projeto formativo alinhado com suas bases filosóficas, políticas e pedagógicas, no qual estejam engajados docentes e estudantes.

No Brasil, as proposições das Diretrizes Curriculares Nacionais (DCNs) são basilares para a estruturação dos currículos, pois incorporam a base das atividades formativas envolvidas em uma concepção de formação abrangente e sistêmica, de acordo com as demandas da atualidade.

Dessa forma, propõe-se a organização curricular dos cursos EaD em módulos constituídos por unidades de aprendizagem. Trata-se de uma organização curricular que articula núcleos, módulos temáticos e unidades de aprendizagem. Na perspectiva da $\mathrm{EaD}$, lança-se o desafio de constituir uma dinâmica curricular pautada na interconexão dos conteúdos, nas interfaces dos conhecimentos e na sua transversalidade, denominada de Cata-ventos Pedagógicos, conforme a representação gráfica da Figura 1.

De acordo com a Figura 1, os núcleos são basilares para a estrutura metodológica para organização curricular do curso, pois sustentam as atividades formativas envolvidas em uma concepção de formação acadêmica abrangente e sistêmica, de acordo com as demandas da atualidade.

Assim, a partir do que é expresso em cada núcleo, propõe-se um currículo que permite aos ensinantes e aprendentes o estabelecimento de conexões e interconexões entre os conhecimentos científicos específicos das unidades de aprendizagem com as práticas sociais e 
com a integralidade desses conhecimentos.

Os módulos são, portanto, temporais e metodológicos, caracterizam-se como temporais, pois organizam a integralização da dinâmica curricular na duração do curso, e metodológicos, pois são constituídos de temas que agregam os conteúdos do curso.

As Unidades de Aprendizagem se caracterizam por serem conceituais e metodológicas. São conceituais porque definem os conhecimentos específicos a serem trabalhados em cada módulo, e metodológicas porque seu objetivo é criar meios para que o ensino e a aprendizagem sejam pensados e operacionalizados na sua integralidade, ou seja, buscando a superação da fragmentação do conhecimento. Portanto, elas se constituem na inter-relação entre os seus conteúdos específicos.
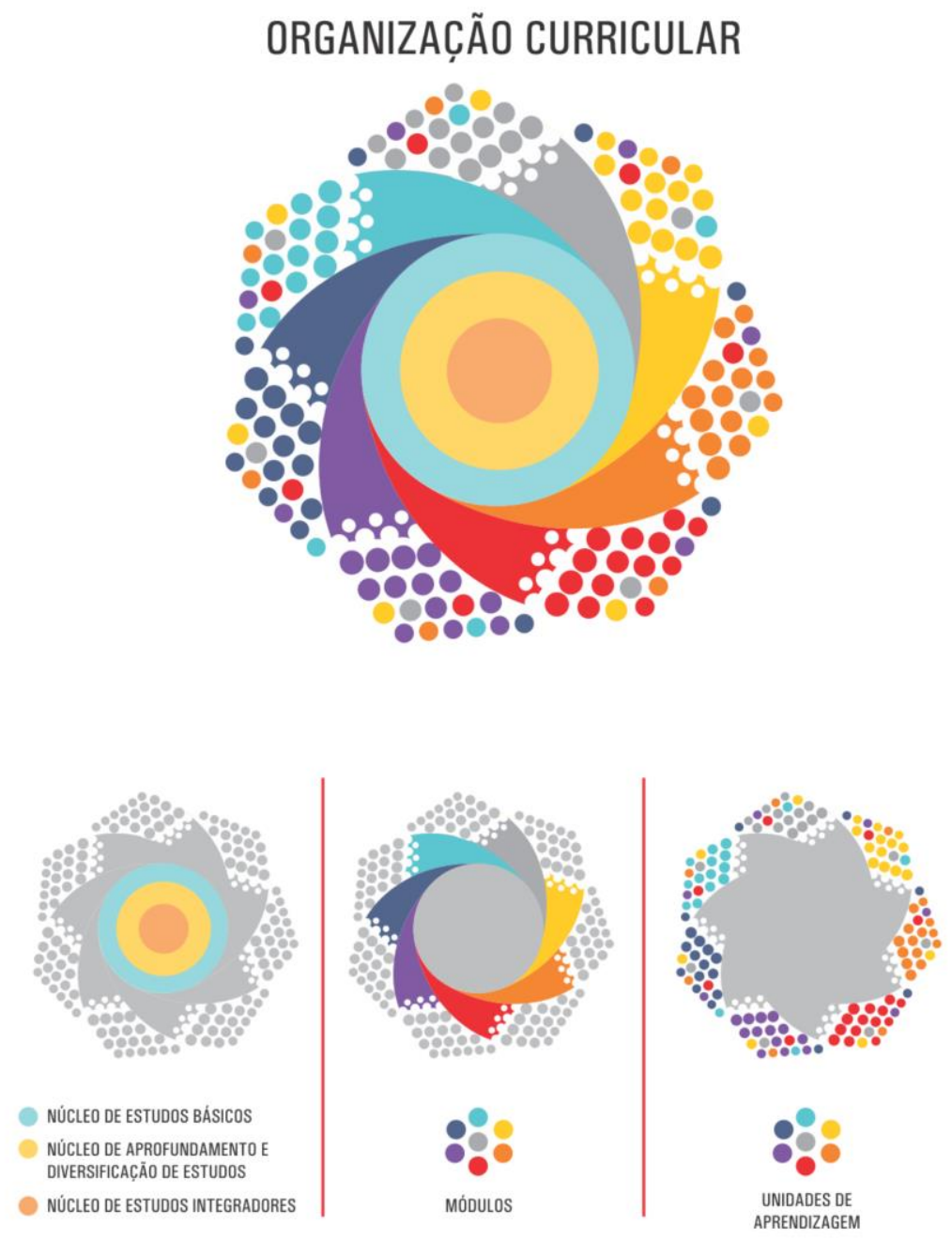
Figura 1. Representação Gráfica da Organização Curricular do Curso de Graduação EaD - Cataventos Pedagógicos.

Fonte: as autoras, 2017.

Desse modo, a operacionalização no Ambiente Virtual de Aprendizagem (AVA) está dividida em módulos estruturados em unidades de aprendizagem. Cada unidade possui atividades e tarefas de interação e de avaliação. Assim, a intenção é materializar a [inter] relação entre as partes e o todo do conhecimento sem perder a especificidade de cada área do saber.

O planejamento e o desenvolvimento de cada módulo são construídos de modo compartilhado entre os profissionais envolvidos no curso. O intuito é que o aluno compreenda os conhecimentos construídos durante o curso na sua integralidade.

Portanto, destaca-se a necessidade de se trabalhar os conteúdos de forma articulada pois,

[...] a superação da visão fragmentada do conhecimento e dos processos naturais e sociais enseja a estruturação curricular por meio da interdisciplinaridade e contextualização. Partindo da ideia de que a realidade só pode ser apreendida se for considerada em suas múltiplas dimensões, ao propor o estudo de um objeto, busca-se não só levantar quais os conteúdos podem colaborar no processo de aprendizagem, mas também perceber como eles se combinam e se interpenetram (BRASIL, 2007, p. 9).

Entretanto, a proposta deste curso contempla a interdisciplinaridade a partir do conceito de [inter]relação entre as Unidades de Aprendizagem. Os temas que caracterizam cada módulo são desenvolvidos a partir de Unidades de Aprendizagem que pontuam os conhecimentos a serem trabalhados. A materialização dessa proposta implica que as práticas pedagógicas no âmbito do curso estejam focadas em concretizar a [inter]relação entre as unidades de aprendizagem. Este conceito é compreendido como a possibilidade de integração das unidades em um constante movimento relacional.

Portanto, na dinâmica curricular, a [inter]relação entre as unidades tem o propósito de incitar os sujeitos envolvidos no processo a desconstruir concepções fragmentadas sobre a construção do conhecimento. Nessa proposta, a inovação ocorre na perspectiva de romper com a disciplinarização do saber, uma vez que pode dificultar a compreensão global do conhecimento e, consequentemente, o desenvolvimento da capacidade de refletir e atuar nas demandas da heterogeneidade na atuação profissional. Assim, a organização dos conteúdos permitirá o estudo da realidade, contemplando o princípio de contextualização.

Nessa perspectiva, atenta-se para a relação teoria-prática, operacionalizada a partir da transversalidade do ensino e da aprendizagem, caracterizada pela integração e articulação, desde o início do curso, dos conteúdos relacionados aos conhecimentos teóricos, técnicos e práticos do campo de atuação profissional permeados pela educação tecnológica em um movimento de circularidade. 
Assim, esta proposta é um investimento na integração entre o ensino, a pesquisa e a extensão, pois ao propiciar a [inter] relação entre a teoria e a prática, fomenta a ação docente e discente, em trânsito livre com pesquisas que contemplam o princípio científico e educativo.

$\mathrm{Na}$ dinamização do currículo, as temáticas da história e cultura afro-brasileira e indígena, educação ambiental, educação em direitos devem ser trabalhadas de forma transversal, a partir dos conteúdos específicos desenvolvidos nos diferentes módulos (obrigatórios e optativos), bem como em outras atividades institucionais.

\section{PROPOSIÇÃO DA METODOLOGIA DE ENSINO}

Nessa perspectiva, propõe-se a metodologia da problematização como procedimento didático para o desenvolvimento dos módulos. Fundamentados em Delizoicov, Angotti e Pernambuco (2002), propõe-se que a dinamização do trabalho pedagógico tenha como eixo três momentos.

O primeiro momento é da problematização inicial, em que ocorre a apresentação de situações reais conhecidas pelos alunos, as quais permeiam as teorias científicas em estudos. $\mathrm{O}$ conhecimento trazido pelos acadêmicos é problematizado pelos professores e tutores a partir de questões relativas aos temas propostos nos módulos. Os mediadores têm o papel de estimular a discussão, questionando posicionamentos e lançando dúvidas para que o acadêmico seja incentivado a ampliar seus conhecimentos.

O segundo momento é o da organização e sistematização do conhecimento. Para tanto, serão propostas atividades diversas relativas a cada módulo utilizando as ferramentas e os recursos no ambiente AVA.

O terceiro momento propicia situações em que o estudante possa aplicar o conhecimento construído para analisar e interpretar, tanto as situações iniciais como outras que possam ser compreendidas pelo mesmo conhecimento.

Os três momentos devem ocorrer de modo recursivo, pois incidem uns nos outros de modo não linear. Para viabilizar esse processo, os mediadores utilizam as várias estratégias disponíveis nas tecnologias da informação e comunicação aplicadas à educação.

As situações problematizadoras acontecem por meio de fóruns de discussão, material para leitura digital, chats, vídeos e podcasts, exercícios no ambiente virtual, entre outros. Desse modo, explicitam-se conceitualmente algumas das estratégias que são meios para desenvolver a metodologia do trabalho pedagógico:

a) Fórum: é um importante instrumento pedagógico virtual, que tem por objetivo 
proporcionar educação sem distâncias. O fórum pode ser um espaço para dirimir dúvidas ou ponto de encontro para discussões acerca de temáticas da área.

b) Vídeos e Podcasts: o grupo de professores que trabalha nos módulos pode elaborar vídeos com apresentações de conteúdo ou aulas expositivas, quando necessário. Também pode indicar vídeos por meio de links, mesmo que estejam hospedados em outras páginas da web. Além disso, dependendo da especificidade de cada módulo, podem preparar podcasts para a dinamização das aulas.

c) Material digital para leitura: embora as estratégias e materiais de ensino em EaD sejam variados, é necessário que o curso elabore material digital, composto por livros ou polígrafos preparados pelos professores, de forma que o aluno possa lê-lo online, fazer download ou imprimi-lo a qualquer momento, já que o ensino a distância pode ocorrer de forma assíncrona ou síncrona.

d) Chat: essa ferramenta permite que alunos e professores reúnam-se em horário préestabelecido para debater conteúdo ou elaborar apresentações de trabalhos, de forma síncrona.

e) Exercícios e tarefas: conforme a particularidade de cada módulo, os professores podem preparar exercícios dissertativos ou objetivos. Em certos casos, o aluno pode obter automaticamente a resposta de cada questão. O ambiente Moodle permite muitos subsídios para que o acadêmico possa ampliar a construção do conhecimento, como: o envio de arquivo único, questões de múltipla escolha, wikis, questionários e diário.

A partir dessa dinâmica, são oferecidas as atividades interativas no ambiente virtual. Também são previstos encontros presenciais para que os sujeitos envolvidos no processo estabeleçam vínculos como parte da comunidade acadêmica, bem como para consolidar aprendizagens, por meio da interação com tutores, colegas e professores. Para tanto, são previstos encontros presenciais nos ambientes físicos dos polos. Esses encontros poderão ser divulgados no início de cada módulo, por meio do plano de aprendizagem.

Dessa forma, busca-se criar condições para que o aluno desenvolva a capacidade de articular conceitos científicos com as situações da atividade docente, ou seja, atender ao princípio da relação teoria-prática a partir do processo dialógico estabelecido.

Logo, investe-se em um trabalho pedagógico contando com diversos mediadores que conduzam os acadêmicos à reflexão, à teorização e à significação da sua ação.

a) Coordenador de polo: cada polo vinculado à sede da IES terá seu próprio coordenador, que é responsável por gerir as questões acadêmico-administrativas. b) Tutores presenciais: os tutores presenciais deverão estar presentes nos polos da IES (pelo menos, um tutor por polo) e aptos a esclarecer questões como calendário acadêmico, data de provas presenciais, horário

\begin{tabular}{l|l|l|l|l|l}
\hline (c) Rev. Inter. Educ. Sup. & Campinas, SP & v.4 & n.3 & p.510-520 & set./dez. 2018 \\
\hline
\end{tabular}


de atendimento dos polos e demais dúvidas que surgirem quanto a questões acadêmicoadministrativas. c) Tutores a distância: $\mathrm{O}$ curso deverá contar com um tutor a distância para cada 30 alunos e cada tutor deverá possuir experiência nas áreas nas quais atua. $\mathrm{O}$ tutor auxilia o professor no atendimento dos alunos ao ser capacitado para esclarecer dúvidas quanto ao conteúdo trabalhado e demais questões pedagógicas que surgirem ao longo do curso.

Portanto, essa proposta metodológica compreende que o aluno é o centro do processo de construção do conhecimento. Sob essa perspectiva, a metodologia do trabalho pedagógico do curso deverá estar alicerçada no pilar da interatividade, uma vez que ela é fundamental para qualidade do curso a distância (BRASIL, 2007). Nessa proposta, a avaliação é entendida como contínua, o que implica avaliar o estudante no seu processo de construção do conhecimento a partir das diversas modalidades de avaliação de forma [inter]relacionada.

Assim, o sistema avaliativo tem como objetivo promover a aprendizagem do acadêmico. Para tanto, o processo de avaliação é realizado a partir de três dimensões: diagnóstica, formativa e somativa, em que a centralidade do processo é a avaliação formativa.

A dimensão diagnóstica tem como função investigar e conhecer o que o aluno sabe e o que ainda necessita avançar na construção de seus conhecimentos, subsidia o professor a identificar os entraves, sucessos e desafios do processo de ensino e de aprendizagem. Dessa forma, permite aos sujeitos envolvidos no processo educativo da $\mathrm{EaD}$ o redirecionamento, a [re]orientação do planejamento para a ação pedagógica.

A avaliação formativa tem a finalidade de colocar os estudantes como participantes do processo; possibilitando meios para a construção de habilidades de autoavaliação e avaliação onde eles possam perceber como esta sua trajetória de aprendizagem, isto é eles "[...] têm a oportunidade de julgar a qualidade do seu próprio trabalho e do trabalho dos colegas, a partir de objetivos de aprendizagem bem definidos e critérios adequados de avaliação" (VILLAS BOAS, p. 5, 2006). Já a avaliação somativa, de acordo com Haydt (2000), tem como função classificar os estudantes, segundo os níveis de aproveitamento apresentados. Geralmente é realizada ao final de uma unidade de estudo, semestre ou ano letivo, e frequentemente se baseia nos conteúdos e procedimentos de medida, como provas, teste com questões objetivas e ou dissertações-argumentativas.

Assim, destaca-se que as três dimensões avaliativas sejam efetivadas na prática de ensino de modo [inter]relacionado. Para tanto, serão utilizados indicadores quantitativos e qualitativos. Sob esse enfoque, entende-se que a avaliação é cumulativa, contínua e não circunstancial; é reveladora de todo o processo de ensino e de aprendizagem e não apenas de seu produto. Portanto, os instrumentos avaliativos serão adotados em diferentes momentos, de forma precisa e sistemática. 


\section{CONSIDERAÇÕES FINAIS}

A necessidade de repensar a formação de profissionais para a atuação na sociedade que se apresenta em constantes transformações vem desafiando os cursos de formação em termos curriculares e metodológicos. Nesse sentido, a proposição de novas modalidades de ensino, bem como inovações curriculares são fundamentais para atingir os objetivos formativos contemporâneos.

Observa-se que propostas curriculares e metodológicas diferenciadas têm em comum a busca por algo que venha a superar o paradigma curricular vigente de formação de profissionais. A modalidade $\mathrm{EaD}$ tem sido um espaço profícuo para a elaboração de inovações, pois permite maior flexibilidade nas propostas de formação.

A proposta Cata-ventos Pedagógicos pode se constituir como base para a organização curricular de outros cursos de formação inicial da Instituição. Essa prevê atividades programadas para o planejamento dos cursos, constituindo uma base sólida no que tange à formação, a qual está articulada por núcleos, módulos temáticos e unidades de aprendizagem. $\mathrm{Na}$ perspectiva da $\mathrm{EaD}$, lança-se o desafio de constituir uma dinâmica interdisciplinar pautada na interconexão dos conteúdos, nas interfaces dos conhecimentos e na sua transversalidade. Assim, está ancorada em uma proposta metodológica que incita a busca de conhecimento e capacidade de aprender de forma uma autônoma e colaborativa.

Para tanto, faz-se necessário o engajamento da gestão institucional, investindo na valorização da mudança, no investimento em infraestrutura e na formação dos professores. Por parte dos docentes, é fundamental que eles assumam o compromisso com o novo projeto e com a reorganização dos tempos e espaços de aprendizagem.

\section{REFERÊNCIAS}

BRASIL, Lei 4.024/61, de 20 de dezembro de 1961. Estabelece as Diretrizes e Bases da Educação Nacional. Disponível em:

https://presrepublica.jusbrasil.com.br/legislacao/108164/lei-de-diretrizes-e-base-de-1961-lei4024-61 Acesso em: 18/03/2018.

BRASIL, Decreto $\mathbf{N}^{\mathbf{0}}$ 5.622, de 19 de dezembro de 2005. Regulamenta o art. 80 da Lei no 9.394, de 20 de dezembro de 1996, que estabelece as diretrizes e bases da educação nacional. Disponível em: http://portal.mec.gov.br/seed/arquivos/pdf/dec_5622.pdf Acesso em: 22/02/2018.

BRASIL, Referenciais de qualidade para educação superior a distância, 2007. Disponível em: http://portal.mec.gov.br/seed/arquivos/pdf/legislacao/refead1.pdf Acesso em: 11

\begin{tabular}{|l|c|c|c|c|c|}
\hline (C) Rev. Inter. Educ. Sup. & Campinas, SP & v.4 & n.3 & p.510-520 & set./dez. 2018 \\
\hline
\end{tabular}


mai.2017.

CENTRO UNIVERSITÁRIO FRANCISCANO. Plano de Desenvolvimento Institucional (2016-20121). Santa Maria: Editora Unifra, 2016.

DELIZOICOV, Demétrio; ANGOTTI, José. André.; PERNAMBUCO, Marta. Maria. Ensino de ciências: fundamentos e métodos. São Paulo: Cortez, 2002.

FONTANA, R. L. M., et al. A Trajetória da Educação a Distância. Ciências Humanas e Sociais, Aracaju, v. 2, n.2, p. 243 - 255, 2014.

HAYDT, Regina. Cazaux. Avaliação do processo ensino-aprendizagem. São Paulo: Ática, 2000.

LEONTIEV, Alexei. Actividad, conciencia, personalidad. México: Editorial Cartago de México, 1984.

MASETTO, Marcos. Tarcísio. Inovação curricular no ensino superior. Revista ecurriculum, São Paulo, v.7 n.2 Agosto de 2011. Disponível em:

http://revistas.pucsp.br/index.php/curriculum Acesso em: 15 nov. 2017.

VILLAS BOAS, Benigna. Maria de Freitas. Portfólio, avaliação e trabalho pedagógico. Campinas, SP: Papirus, 2006.

VYGOTSKI, Lev. Semyonovich. A formação social da mente. São Paulo: Martins Fontes, 2003.

\section{Sobre os autores}

${ }^{1}$ Greice Scremin ${ }^{10}$

E-mail: greicescremin@gmail.com

Universidade Franciscana - Brasil

Doutora em Educação - Universidade Federal de Santa Maria [UFSM].

${ }^{2}$ Eliane Aparecida Galvão dos Santos ${ }^{(\mathbb{D}}$

E-mail: elianeagalvão1 @gmail.com

Universidade Franciscana - Brasil

Doutora em Educação - Universidade Federal de Santa Maria [UFSM].

\section{${ }^{3}$ Elisiane Machado Lunardi ${ }^{(D)}$}

E-mail: Elisiane.lunardi@gmail.com

Universidade Federal de Santa Maria - Brasil

Doutora em Educação - Pontifícia Universidade Católica do Rio Grande do Sul [PUCRS]. 